\title{
Forward modeling using finite difference method for fractured hard rocks tracing via three-electrode array
}

\author{
(C) Reza Ghanati, Babak Aranifar, Mohammad Kazem Hafizi, 2013
}

\author{
Institute of Geophysics, University of Tehran, Tehran, Iran \\ Received 4 August 2012 \\ Presented by Editorial Board Member E. D. Kuzmenko
}

\begin{abstract}
У статті наведено результати польових електророзвідувальних робіт на півночі Ірану, отримані трьохелектродною установкою. Виконано 2D інверсію значень уявного опору, що дозволила локалізувати області з низьким питомим опором в товщі високоомних порід, пов'язані в основному із зонами тріщинуватості. Результати інверсії підтверджені бурінням.
\end{abstract}

\begin{abstract}
В статье представлены результаты полевых электроразведочных работ на севере Ирана, полученные трехэлектродной установкой. Выполнена 2D инверсия значений кажущегося сопротивления, позволившая локализовать области с низким удельным сопротивлением в толще высокоомных пород, связанные в основном с зонами трещиноватости. Результаты инверсии подтверждены бурением.
\end{abstract}

Introduction. The electrical resistivity method is highly useful to investigate the nature of subsurface formations by studying the variations in their electrical properties. This method is assumed to be of considerable importance in subsurface exploration because of very high resistivity contrasts among the lithological units, controlled depth of investigation, ease of field operations and low cost of instrumentation and operation. In this method, artificially generated electrical currents are supplied to the earth and the resulting potential differences are recorded. In hard rock areas within which the earth normally has high resistivity, due to presence of fractures and water accumulation into fractures, resistivity dramatically decreases, hence an electrical resistivity survey results in low resistivity anomalies. Such anomalies are interpreted to indicate areas of potentially significant ground water flow. In other words, the location of potential fracture zones in hard rock area is extremely important to yield large amounts of groundwater and this can be done using geoelectrical approaches such as three-electrode array. Mutually mirrored three-electrode arrays AMN and MNB have been used in various forms in order to detect different targets by some resear- ches, [Блох, 1962; Gruntornd, Karous, 1972; Karous, 1982]. These studies proved that two-sided three electrode configurations are more suitable than classical full array (Schlumberger, Wenner) over a complex geology [Candansayar, Basokur, 2001]. Karous and Pernu (1985) combined the sounding and profiling techniques by means of AMN and MNB half-Schlumberger arrays. The main aim of these authors was to identify thin conductors. Schulz and Tezkan [Schulz, Tezkan,1988] recorded Schlumberger and the corresponding half-arrays simultaneously to examine the dimensionality of the subsurface. Hafizi [Hafizi, 1998] detected fractures in a hard rock area using combined resistivity profiling and square array techniques. Candansayar and Basokur [Candansayar, Basokur, 2001] applied twosided three-electrode array to reveal small-scale targets. They proved that the three-electrode array has better resolution for detection of small targets compared to its four-electrode counterpart and dipole-dipole data.

In this paper, we initially review combined resistivity sounding-profiling measurements with the three-electrode arrays and the literature dealing with the use of this method applied to geological struc- 
tures. Then, we describe the modeling process in the software using the finite difference method: In addition in order to evaluate the software accuracy, we compared the results obtained from the provided software, the "Exact solution" (obtained from the electrical image theory [Telford et al., 1976] and the results of Res2DMod commercial software). Finally we discuss the pseudo-section and inverted section derived both from the field and modeling data.

Description of the combined resistivity sounding-profiling system. This array is a combination of two electrode arrays with three electrodes ( one current electrode is placed at infinity) which are similar to the two-half Schlumberger setup with the current electrode at the left and the right, respectively. The infinity current electrode is perpendicular to the profiling strike. In the field procedure, two apparent-resistivity values are measured by switching on the current between two current electrodes that are located on the left- and right-hand sides of the array center. The resistivity data from such asymmetrical arrays can be processed and presented in various ways to emphasize the different survey objectives, e. g. bed rock topography, conductive or resistive dykes, contacts between rock formations with different resistivity [Karous, Pernu, 1985].

Fig. 1 shows a scheme of the combined sounding-profiling array. The apparent resistivity associated with this array for the left and the right halfSchlumberger configurations is calculated with the following formula:

$$
\rho_{a}=2 \pi \frac{\Delta V}{I\left[\frac{\left(L_{i}+d\right)\left(L_{i}-d\right)}{2 d}\right]} .
$$

Where $I$ indicates current injected into the ground, $V$ denotes the voltage difference between potential electrodes, $L_{i}$ is the distance of the current electrodes $(A$ and $B$ ) from the configuration center and $d$ shows the distance of two potential electrodes

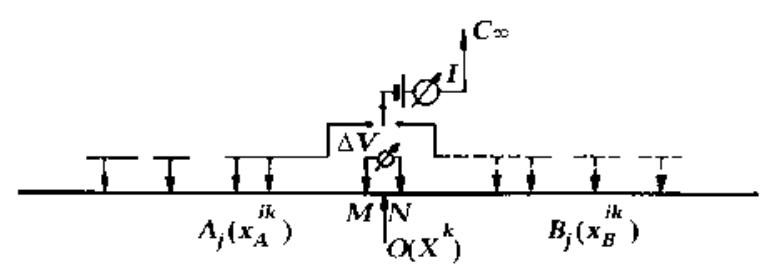

Fig. 1. Schem of the combined sounding-profiling array (two three electrode arrays AMN \& MNB). for the $i$ th reading. According to the principle of superposition, the apparent resistivities $\rho_{a}^{i k}$ for the corresponding symmetrical Schlumberger array are the mean values of those for the two three-electrode arrays AMN and MNB [Karous, Pernu, 1985]:

$$
\rho_{a}^{i k}=\frac{\rho_{A}^{i k}+\rho_{B}^{i k}}{2}, \quad i=1, \ldots, M, k=1, \ldots, N .
$$

One advantage of this array is that it is able to detect vertical contacts, as dykes and steeply dipping faults [Karous, Pernu, 1985]. Sounding-profiling measurements are mutually carried out in two opposite directions. Profiling curves obtained for AMN and MNB arrays, due to existence of anomaly, intersect each other. In other words, the inequality between the apparent resistivity values obtained from the corresponding AMN and MNB configurations can be used to locate a resistivity heterogeneity along the profile direction [Candansayar et al., 1999]. In combined sounding-profiling array additional to computation of resistivity curves for AMN and MNB based on distance, the so-called gradient transformation which has been proposed by Karous [1979, 1982] given as:

$$
G^{i k}=\frac{\rho_{A}^{i k}}{\rho_{A}^{i, k+1}}+\frac{\rho_{B}^{i k}}{\rho_{B}^{i, k-1}}-2 .
$$

Where $G$ indicates Gradient Transformation, $i$ denotes the number of the reading in the left- and rightarrays and $k$ is the number of the sounding station.

This transformation generates profile curves of gradient $G$ with sharp local maxima above the mentioned anomalies.

Modeling using finite difference method. In the forward modeling problem, the subsurface resistivity distribution is specified a priori and the purpose is to calculate the apparent resistivity that would be measured by a survey over such resistivity distribution. A forward modeling subroutine is in fact as an essential part of any inversion program since it is necessary to calculate the apparent resistivity values for the model produced by the inversion routine to see whether is agrees with the measured values. A limited number of numerical solutions of 3D direct current (DC) resistivity problem have been discussed in the geophysical literature. These solutions have been obtained using integral equation or finite difference and finite element approaches [Roy, 2008]. Each method has its own par- 
ticular advantages and is better suitable for specific geometrics. The integral equation method, for instance, only considers the charge on the surface of a body. The 3D forward modeling using the integral equation technique is very fast and requires less computer memory, but is restricted only to certain model geometrics. Finite-difference and finite-element methods, however, are suitable for modeling an arbitrarily complex 3D earth. Dey and Morrison [Dey, Morrison, 1979 b] developed a 3D finite difference algorithm to evaluate the potential for a point current source. In engineering and environmental surveys the subsurface can have an arbitrary resistivity distribution, so the finite difference and finite element methods are usually the only viable choice [Loke, 2004].

Hence, in this study, for calculating the following equation which governs the $3 \mathrm{D}$ geoelectric field resulted by a point source, we applied finite difference method:

$$
\begin{gathered}
{[\sigma(X, Y, Z) \nabla \varphi(X, Y, Z)]-} \\
-I / \Delta V\left[\delta\left(X-X_{\downarrow_{s}}\right) \delta\left(Y-Y_{\downarrow_{s}}\right) \times\right. \\
\left.\times \delta\left(Z-Z_{\downarrow_{s}}\right)\right],
\end{gathered}
$$

where $\sigma$ represents the conductivity, $I$ is the injected current, $\delta$ is the electrical potential. Subject to the following boundary conditions, equations (5) and (6) indicate Neumann Dirac delta function, and $X_{\downarrow_{s}}$, $Y_{\downarrow_{s}}, Z_{\downarrow_{s}}$ are coordinates of the point source of injected current $\varphi$ is and mixed boundary conditions, respectively [Dey, Morrison, 1979 b]:

$$
\begin{gathered}
\frac{\partial \varphi}{\partial n}=0 \in \Gamma_{s}, \\
\frac{\partial \varphi}{\partial n}+\frac{\cos \theta}{r} \varphi=0 \in \Gamma_{\infty} .
\end{gathered}
$$

Where $\Gamma_{s}$ indicates the flat earth-air interface. $\Gamma_{\infty}$ denotes the subsurface external boundaries, and $\theta$ is the angle between the radial distance $r$ from the source point and the outward normal spatial coordinate $n$ on the boundary [Xiaoping et al., 2003].

The executed modeling consists of three steps (1) discretization, (2) linear equation generation and (3) linear equation solution based on iteration methods. In this study, the gridding (discretization) is comprised of two stages. At the first stage, grid- ding points are characterized in terms of electrical conduction differences in which an attempt is made to calculate the contrast between two media precisely. Dimensionally, the cube which is in charge of storing elements on the boundary surface (between two different media) is considered smaller than the other cubes. At the second stage, the gridding is applied to the used electrode configuration. The gridding points include three particular points such as (1) appearance points of the current and potential electrodes (2) middle points of the electrodes which are used to smooth the applied intervals (3) the points added to intervals between the electrode configuration and physical infinity boundary, which these points are situate with the particular intervals from the boundary points of the corresponding electrode configuration to the physical infinity.

After completion of the two above mentioned stages. The next stage is to combine the two grids in which the points of the two are shared at the same set. Then, the simplification process is conducted on the set. In this paper, the rules executed for simplification, include elimination of the repetitive points and combination of the similar points. At the end, it is expected that a grid with suitable and regular points is resulted. As previously mentioned, we used the iteration methods in order to solve the linear equation obtained from the prior stage. In this study, we applied finite difference method as well as mixed boundary conditions (equation 2), analogous to the technique used by Dey and Morrison [Dey, Morrison, 1979a]. Hence, calculation of coefficient matrix based on these two standpoints (i. e. finite difference method and combined boundary conditions) leads to a linear equation [Mufti, 1976].

The iterative methods are divided into two general groups (i. e. stationary iterative methods and nonstationary iterative methods). Successive Over Relaxation (SOR), Jacobi and Gauss — Seidel are stationary iterative methods and Generalized Minimal Residual (GMR), Conjugate Gradient (CG) and Incomplete Cholseky Conjugate Gradient (ICCG) are non-stationary iterative methods, used for solving the linear equation acquired from the previous stage. Moreover, for comparing each method performance, a 1D simple Laplace equation was assumed, which any each technique efficiency with increase of unknown points in Laplace equation was investigated. Fig. 2 shows performance of Jacobi, Gauss - Seidel, SOR, CG and GMR techniques: CG has better performances compared to other methods, however, GMR apparently indicates the best performance, but note that, in GMR, by changing the ent- 


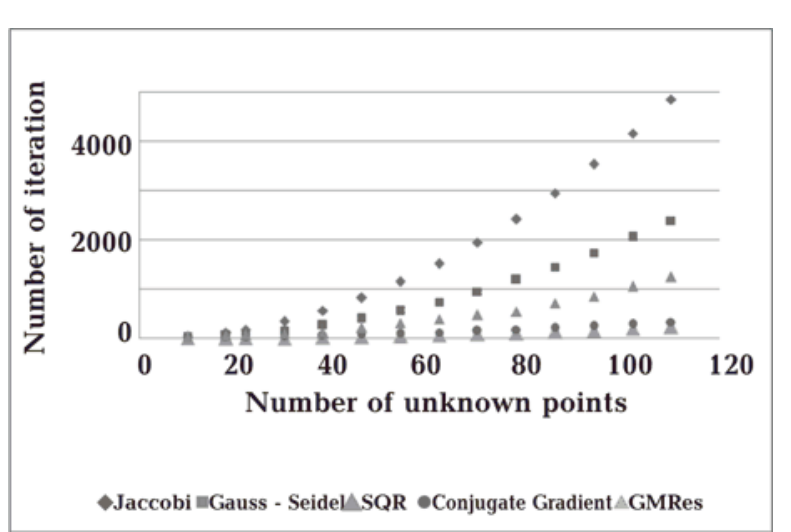

Fig. 2. Performance of Jacobi, Gauss - Seidel, SOR, $\mathrm{CG}$ and GMRes techniques in terms of number of unknown points and number of iteration.

ry parameters such as step factor, exposes a different status form the other methods, thus it does not show an appropriate flexibility compared to $C G$ or ICCG. Whereas, ICCG is derived from the CG method which coverages is much more quick and requires much less computer storage [Xiaoping et al., 2003] thus, we utilized the ICCG method in the provided software.

For testing the software, it should be compared with the systems which theoretically have analytical responses. Hence, we took advantage of a medium including a vertical fault which the left- and right-hand sides of the fault have resistivity 100 and 10 , respectively. Then, the measurements were conducted over the model using pole-pole configuration with electrode spacing $1 \mathrm{~m}$ [Chandra, Singh, 2004]. The results obtained from the software, the "Exact solution" (obtained from the electrical image theory [Telford et al., 1976] and Res2DMod software were compared with each other (Fig. 3). As in-

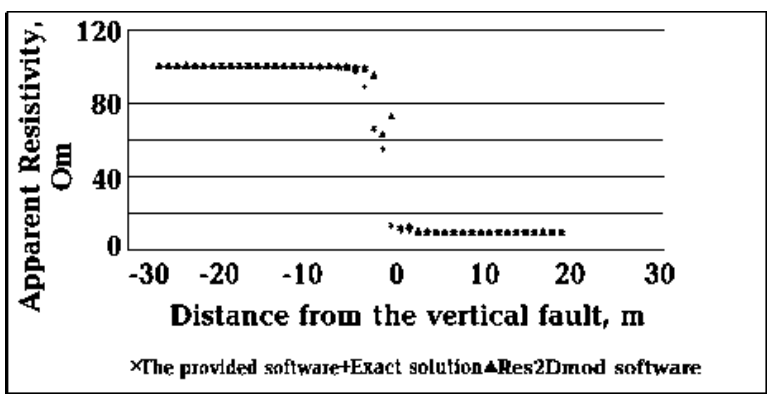

Fig. 3. The results obtained from the provided software, Exact solution and Res2DMod software for a pole-pole array on the synthetic model. ducted from Fig. 3, the responses of the Res2DMod software to the model represent higher deviation in comparison with the provided software responses.

Geology of the study area. The study area is geologically located in the central Alborz zone in the North of Iran including Formations such as Route, Shemshak, Karaj and contemporary sediments. In this region, the hard rocks covered by a pretty thin mantel ( 2 to $15 \mathrm{~m}$ deep) of weathered soil. The study area suffers from the fractures and faults which form the main groundwater-bearing reservoirs. Fig. 4 shows the geology map and location of the region.

Test on synthetic model and field sur vey application. To evaluate the utility of the provided software and combined sounding-profiling method in detection of a vertical conductive zone, we made a model using the provided software. Fig. 5 shows a representative model that could be encountered in the study area (according to the available trench in the study area). As illustrated, the synthetic model consists of a weathering overburden with resistivity value of $50 \Omega \mathrm{m}$, a vertical fracture zone with resistivity and thickness $20 \Omega \mathrm{m}$, and $30 \mathrm{~m}$, respectively, and two high-resistivity blocks on the left- and right-and sides of the anomaly which have intrinsic resistivity values of $200 \Omega m$ and $500 \Omega m$, respectively. The apparent-resistivity pseudo-section for this model was calculated for combination of the left and right half-Schlumberger configurations (from equation (2)). The sounding spacing is $50 \mathrm{~m}$ and the location of soundings with respect to the anomaly is illustrated on the top of the model. $A B / 2$ values of $1 ; 1,47 ; 2,15 ; 3,16 ; 4,64, \ldots, 316 \mathrm{~m}$ were used at each measurement station. Fig. 6 illustrates the pseudo-section corresponding to the mean values of the two three electrode arrays $A M N$ and MNB on the model (from equation (2)). The apparent-resistivity values show the existence of a lowresistivity zone. The model obtained from the $2 \mathrm{D}$ inversion of the four-electrode array (AMNB) using the "non-conventional array" option in the RES2DINV program is shown in Fig. 7, which indicates a lowresistivity zone in the middle of the section corresponding to the synthetic model. In addition, we conducted a geoelectric survey over a fracture hard rock area which located in Pakdeh, North of Iran, using the combined resistivity sounding-profiling method along one survey line perpendicular to the fault strike direction with five soundings separated by a distance of $50 \mathrm{~m}$ and maximum current electrode spa- 


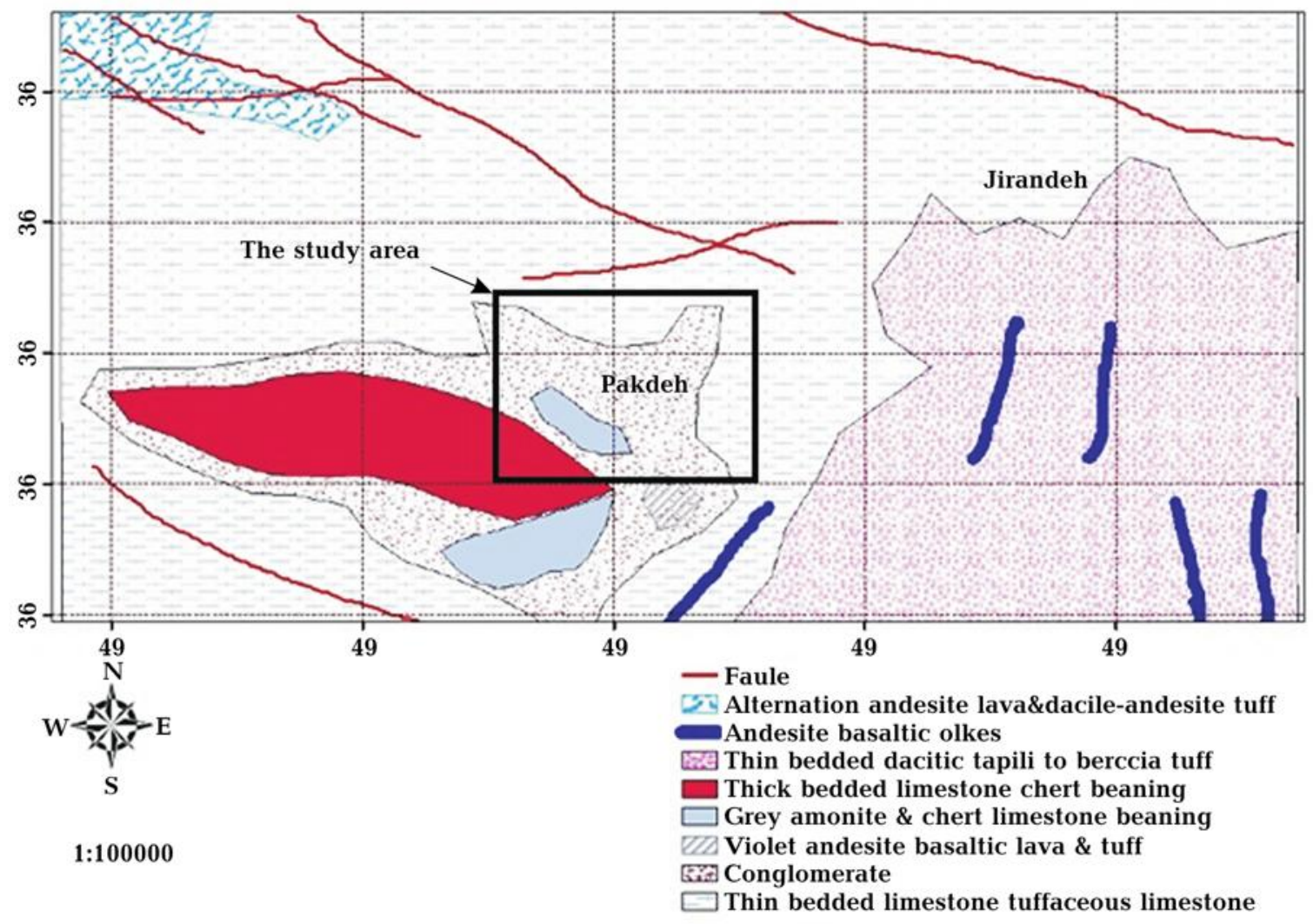

Fig. 4. Sketch of the geological map of the study area.

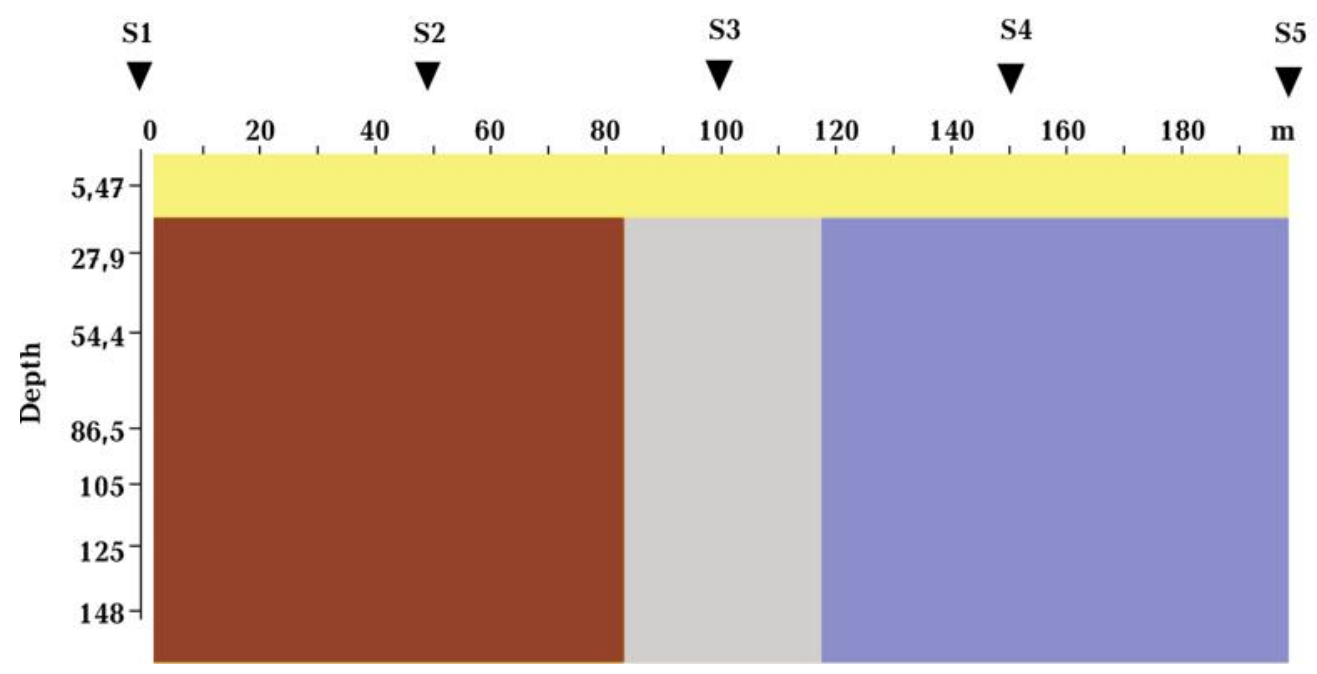

Fig. 5. Synthetic model including a weathered overburden with resistivity value of $50 \Omega m$, a vertical fracture zone with resistivity and thickness equals to $20 \Omega \mathrm{m}$, and $30 \mathrm{~m}$, respectively, and two high-resistivity blocks on the left- and right-hand sides which have resistivity values of $200 \Omega m$ and $500 \Omega m$, respectively. S1 to S5 represent location of the sounding stations. 


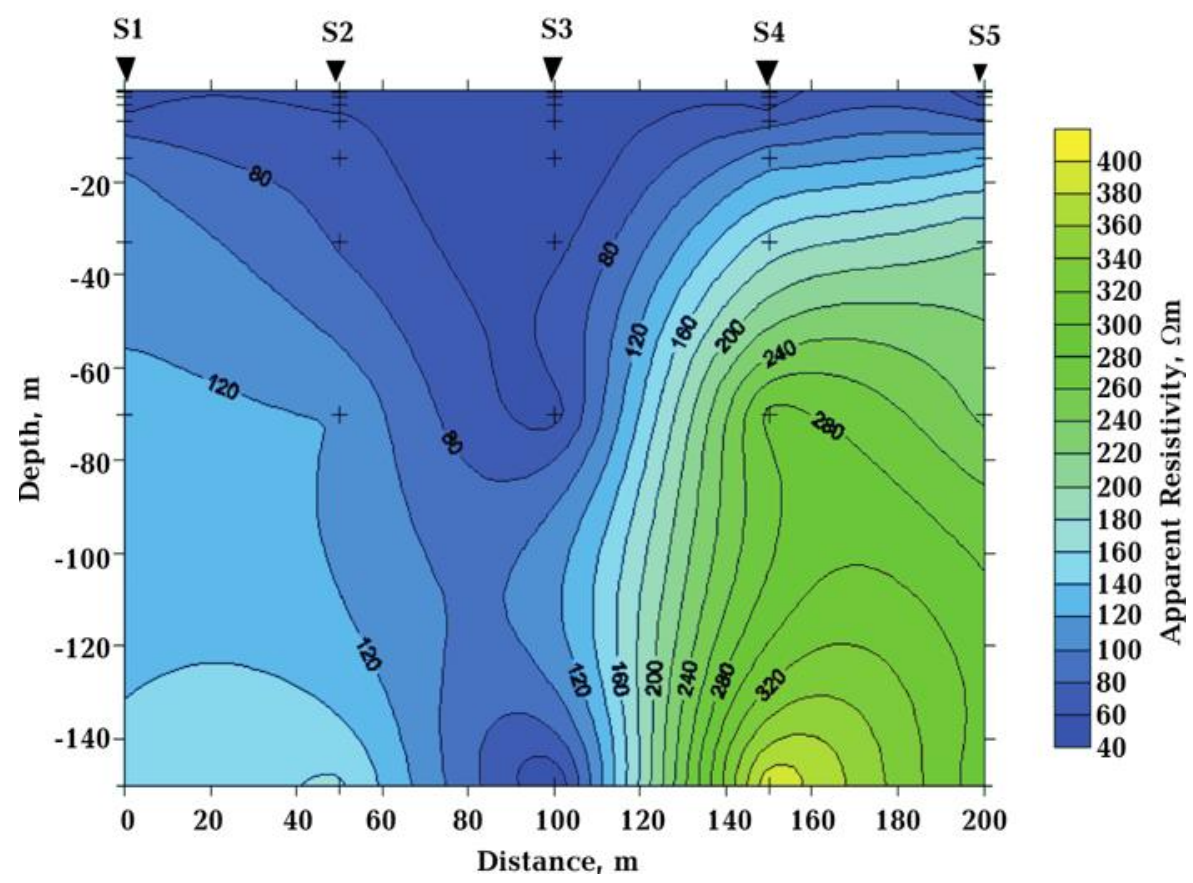

Fig. 6. The pseudo-section presentation of the combination of resistivity values from the two three electrode arrays AMN and MNB on the model.

Iteration 5 RMS error $=11,9 \%$
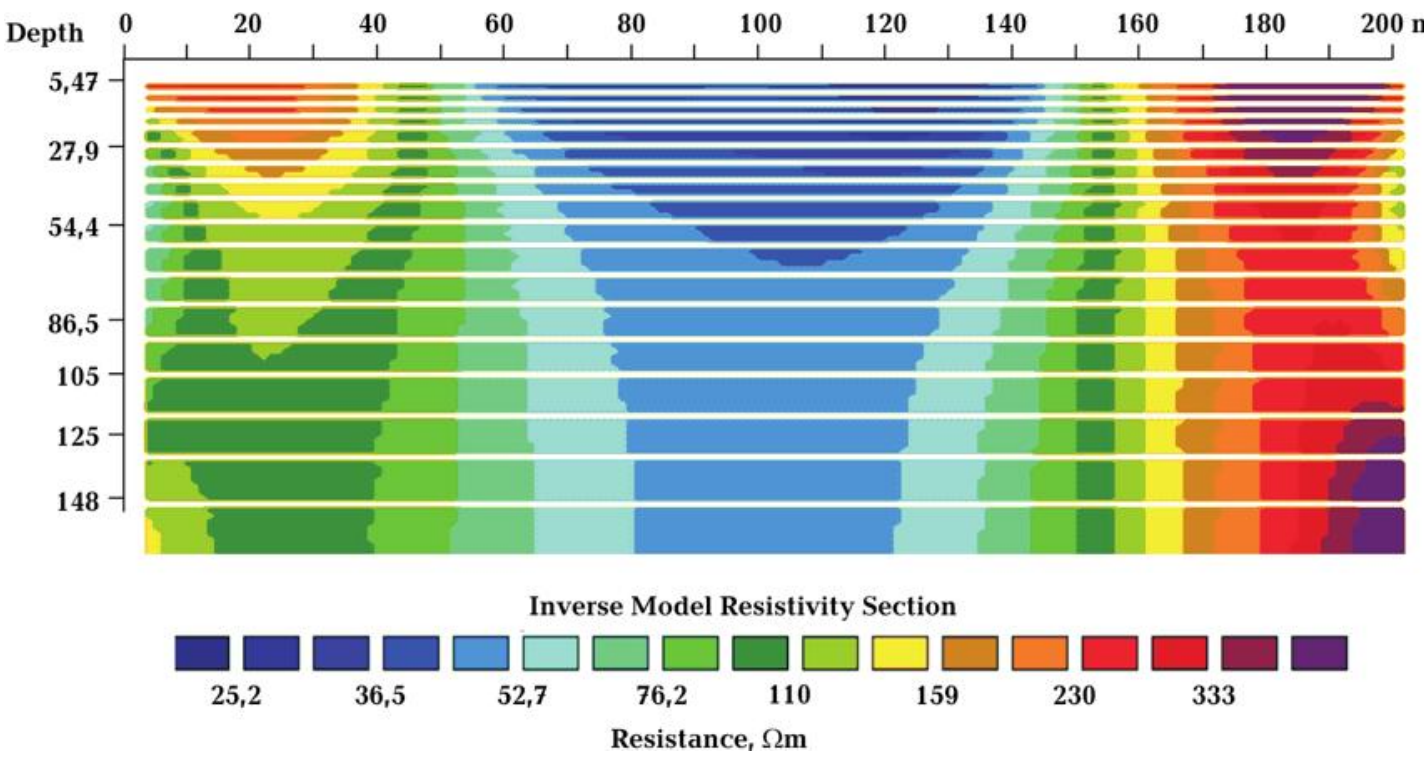

Fig. 7. The 2D inverted model of the four-electrode array (AMNB) using the "non-conventional array" option in the Res2DINV program. 
cing $928 \mathrm{~m}$ a total of 250 apparent-resistivity values were obtained. Sounding locations were selected by geological study as well as by hydrogeological suitability. Fig. 8 and 9 show representative apparent-resistivity pseudo-sections for the values obtained from combination of the left and right HalfSchlumberger arrays from the field measurements and its inverted model by means of the "non-conventional array" option in the RES2DINV program. As seen, the $2 \mathrm{D}$ resistivity section reveals a probable fracture zone between soundings 2 to 3 due to having low resistivity values 30 to $50 \Omega m$ which can be recommended for a drilling (marked by a black arrow) as well as at the location of sounding 4 a re- the model using pole-pole array. The results obtained from the software, the "Exact solution" and Res2DMod software to the synthetic model showed that the responses of the Res2DMod represent higher deviation in comparison with the provided software responses. Furthermore, to examine the proficiency of the software, a fracture zone saturated with water which has lower resistivity to its surroundings, analogous to the study area, using the provided software was modeled and the responses of the model to three-electrode array were calculated. The pseudo-section from the three-electrode array measurements on the synthetic model revealed a low-resistivity zone. Then, we conducted a field sur-

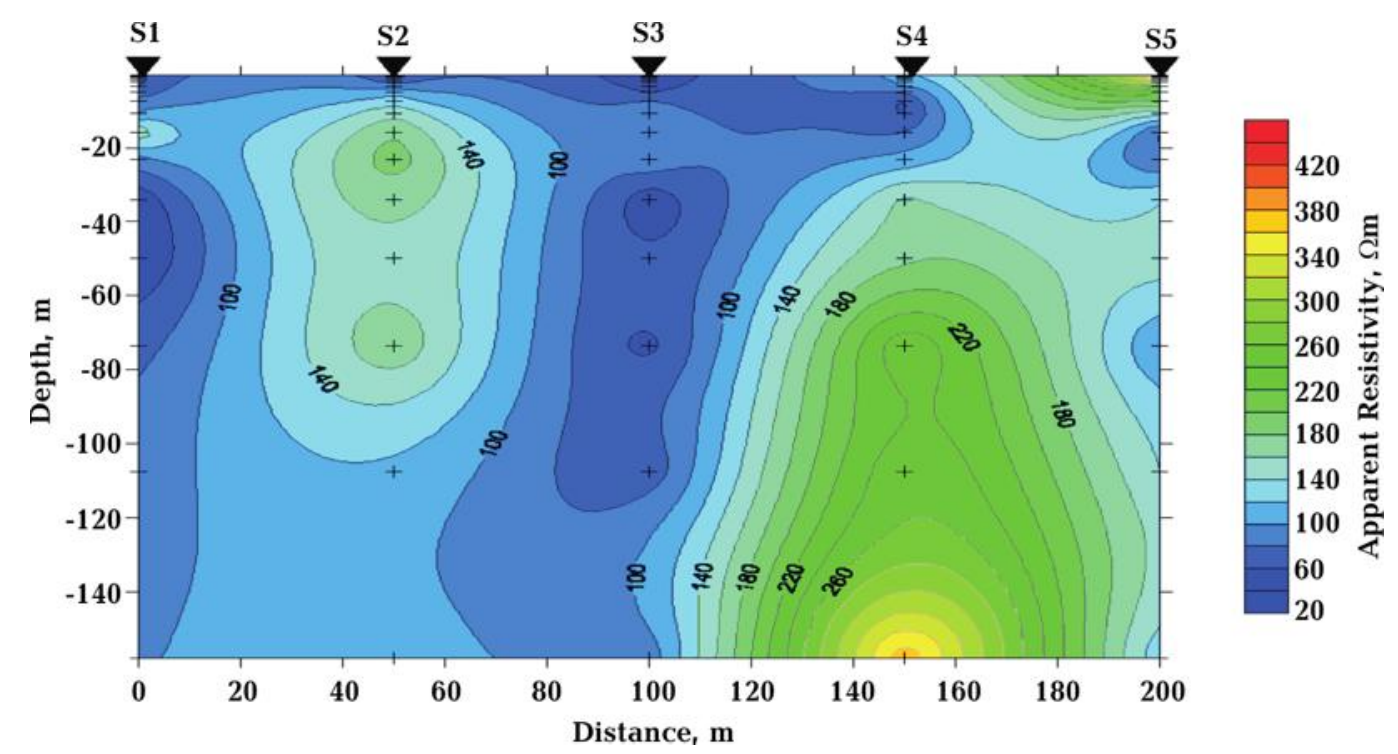

Fig. 8. Apparent-resistivity pseudo-section for the values obtained from combination of the left and right Half-Schlumberger arrays from the field measurements.

latively high resistivity zone exists implicating nonpresence of groundwater flow in there. Furthermore, the finding of geophysical surveys was proved by a tube-well drilled adjacent to the sounding 3 location which yielded a large amount of groundwater.

Discussion and Conclusions. Fractures are the primary source to store and allow movement of groundwater in hard rock areas. The size and location of the fractures, interconnection of the fractures and amount of the material that may be clogging the fractures and recharging sources assess how much water one can get out of the hard rock. The volume of water stored in fractured hard rocks is less compared to the conventional aquifer. There- fore, the location of potential fracture zones in hard rock area is extremely important to have the best chances to extract large amount of groundwater. The efficiency of two Half-Schlumberger arrays AMN and MNB is presented here to map fracture hard rock areas. The anomaly in fact obtained in three electrode array measurements is an indication of the presence of conductive zone in which hard rock areas implicate the existence of fracture zone. In this study, a geoelectric forward modeling was provided and in order to investigate its accuracy, it was compared with systems which theoretically have analytical responses. Thus, we made a synthetic model and some measurements were conducted over 


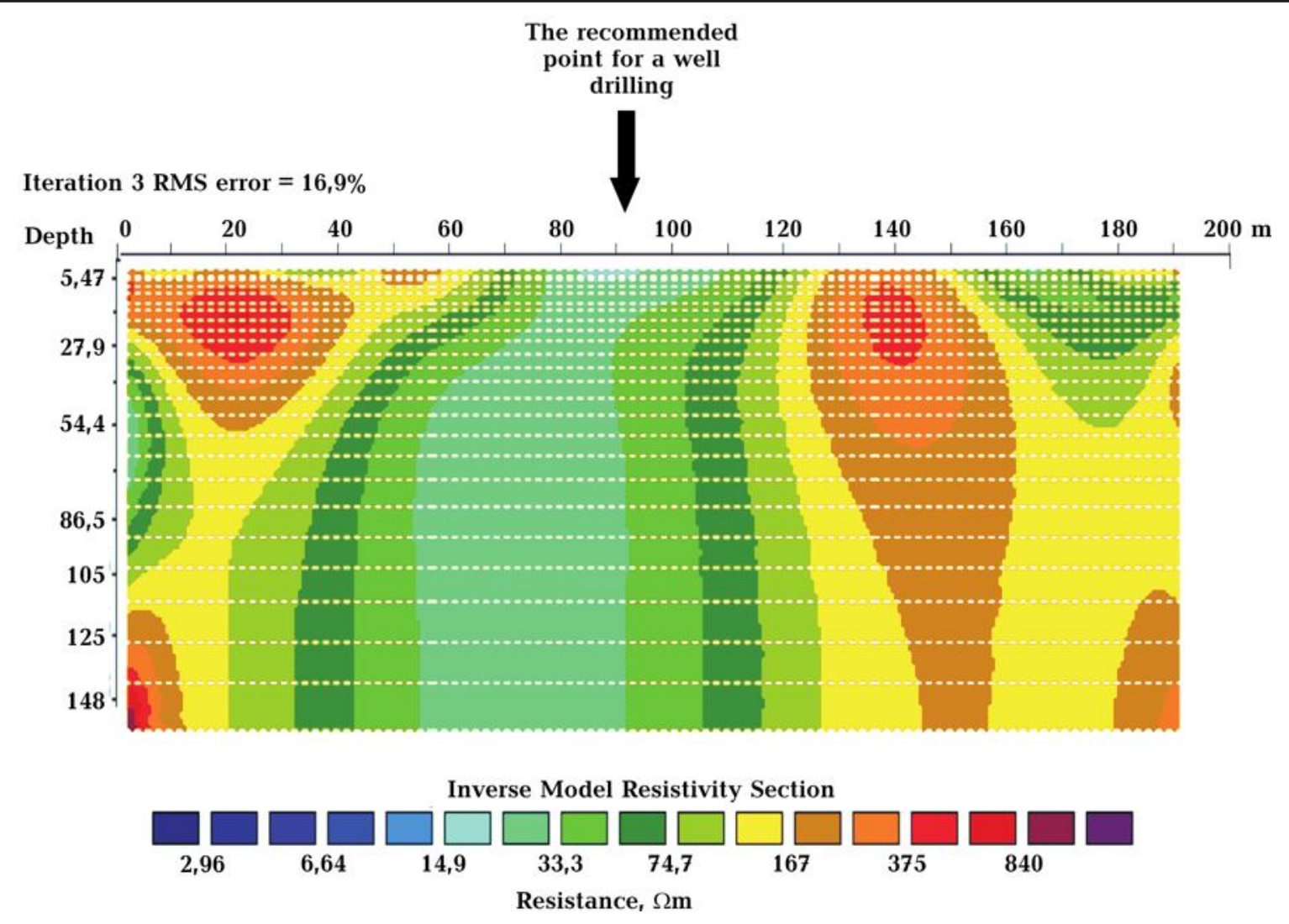

Fig. 9. The 2D inverted model of the four-electrode array (AMNB) using the "non-conventional array" option in the Res2DINV program from the field measurements. The recommended point for drilling is marked by a black arrow.

vey by means of the three-electrode array in a hard rock terrain in the North of Iran. The two-dimensional (2D) inversion of the three-electrode apparent resistivity data led to location of a low-resistivity area implicating the presence of fracture zone in the study area. Drilling of a tube-well resulted in a water-

\section{References}

Блох И. М. Электропрофилирование методом сопротивлений. - Москва: Госгеолтехиздат, 1962. $-239 \mathrm{c}$.

Candansayar M. E., Basokur A. T. Detecting smallscale targets by the $2 \mathrm{D}$ inversion of two-sided three-electrode data: application to an archaeological survey // Geophys. Prospecting. - 2001. 49. - P. 13-25.

Candansayar M. E., Basokur A. T., Peksen E. Detecting small-scale targets by the two-sided gra- bearing zone that the validity of our interpretation was checked. On the other hand, high similarity between the pseudo-sections obtained from modeling and field survey results regarding existence of the fracture zone showed the high proficiency and accuracy of the provided forward modeling software.

dient transformation // J. Balkan Geophys. Soc. - 1999. - 2, N 4. - 100-111.

Chandra S., Singh V. S. A combined approach of Schlumberger and axial pole-pole configurations for groundwater exploration in hard-rock areas // J. Appl. Geophys. - 2004. - 36. - P. 45-55.

Dey A., Morrison H. F. Resistivity modeling for arbitrarily shaped two-dimensional structures // Geophys. Prospecting. - 1979a. - 27. - P. 10201036. 
Dey A., Morrison H. F. Resistivity modeling for arbitrary shaped three-dimensional structures // Geophysics. - 1979b. - 44. - P. 753-780.

Hafizi M. K. Fracture detection in hard rocks using combined resistivity profiling and square array technique // EAGE $60^{\text {th }}$ conference and technical exhibition. - Leipzig, Germany, 1998.

Gruntorad J., Korous M.Geoelektricke metody prbzkumu, Dil I: StejnosmErne metody (Geoelectric methods of exploration, Vol. 1: DC methods, in Czech). - Prague: SNPL, 1972. - 444 p.

Karous M. Gradient curves in resistivity methods with asymmetrical arrangements of electrodes // University of Oulu, Department of Geophysics, Report. - 1982. - № 3. -23 p.

Karous M. Gradientove odporovt kfivky kombinovantho profilovani nad modely (Gradient resistivity curves of combined profiling above models, in Czech) // Acta Univ. Carolinae, Prague, Geologica. - 1979. - № 1-2. - P. 75-100.

Karous M., Pernu T. K. Combined sounding profiling resistivity measurements with the three-electrode arrays // Geophys. Prospecting. - 1985. - 33. - P. 447-459.

Loke M. H. Tutorial: 2D and 3D electrical imaging surveys. - 2004. - http://www.geoelectrical.com/

Mufti I. R. Finite-difference resistivity modeling for arbitrarily shaped two-dimensional structures // Geophysics. - 1976. - 41. - P. 62-78.

Roy K. K. Potential theory in applied geophysics. Springer, 2008.

Schulz R., Tezkan B. Interpretation of Resistivity measurements over 2D structures // Geophys. Prospecting. -1988 . - 36. - P. 962-975.

Telford W. M., Geldart L. P., Sheriff R. E., Keys D. A. Applied geophysics. - Cambridge: Cambridge University Press., 1976. - 860 p.

Xiaoping W., Yifei X., Cheng Q., Tongtong W. Computations of secondary potential for $3 D \mathrm{DC}$ resistivity modeling using an incomplete Choleski conjugate-gradient method // Geophys. Prospecting. - 2003. - 51. - P. 567-577. 